\title{
Arterial compression of nerve is the primary cause of trigeminal neuralgia
}

\author{
Guo-qiang Chen $\cdot$ Xiao-song Wang • \\ Lin Wang $\cdot$ Jia-ping Zheng
}

Received: 11 April 2013/Accepted: 7 August 2013/Published online: 21 August 2013

(c) The Author(s) 2013. This article is published with open access at Springerlink.com

\begin{abstract}
Whether arterial or venous compression or arachnoid adhesions are primarily responsible for compression of the trigeminal nerve in patients with trigeminal neuralgia is unclear. The aim of this study was to determine the causes of trigeminal nerve compression in patients with trigeminal neuralgia. The surgical findings in patients with trigeminal neuralgia who were treated by micro vascular decompression were compared to those in patients with hemifacial spasm without any signs or symptoms of trigeminal neuralgia who were treated with microvascular decompression. The study included 99 patients with trigeminal neuralgia (median age, 57 years) and 101 patients with hemifacial spasm (median age, 47 years). There were significant differences between the groups in the relationship of artery to nerve $(p<0.001)$ and the presence of arachnoid adhesions $(p<0.001)$ but no significant difference in relationship of vein to nerve. After adjustment for age, gender, and other factors, patients with vein compression of nerve or with artery compression of nerve were more likely to have trigeminal neuralgia $(\mathrm{OR}=5.21$ and 42.54, $p=0.026$ and $p<0.001$, respectively). Patients with arachnoid adhesions were less likely to have trigeminal neuralgia $(\mathrm{OR}=0.15, p=0.038)$. Arterial compression of the trigeminal nerve is the primary cause of trigeminal neuralgia and therefore, decompression of veins need not be a priority when performing microvascular dissection in patients with trigeminal neuralgia.
\end{abstract}

G. Chen $\cdot$ X. Wang $(\bowtie) \cdot$ L. Wang $\cdot$ J. Zheng Department of Neurosurgery, Yuquan Hospital of Tsinghua University, 5 Shijing Shan Road, Shi Jing Shan District, Beijing 100049, China

e-mail: waxiso@126.com
Keywords Demyelination - Hemifacial spasm . Microsurgical decompression · Nerve compression · Trigeminal neuralgia

\section{Introduction}

Trigeminal neuralgia is characterized by severe facial pain in the distribution of the trigeminal nerve that is paroxysmal, provokable, unilateral, and not accompanied by sensory loss $[1,2]$. The pain typically lasts only seconds, but is described as excruciating, and is triggered by sensory stimuli that can include chewing, yawning, and speaking [3]. The pain is episodic and pain-free intervals can range from day to years. The incidence of trigeminal neuralgia is reported to be approximately 4 per 100,000 population and gradually increases with age; the condition is rare before 40 years of age and the average age of onset is 60 years [2-5].

Though the condition has been well-studied, there is still debate regarding the pathophysiology. Most experts agree that the etiology is segmental demyelination of trigeminal sensory nerves in the nerve root or brainstem, and the demyelination is due to chronic compression of the nerve root where it exits from the pons $[3,6,7]$. Compression can be due to vascular abnormalities such as an aneurysm or arteriovenous malformation [8], and demyelination due to multiple sclerosis has been described [6]. Most theories, however, consider compression from an artery and/or vein (e.g., superior cerebellar) as the trigeminal nerve exits the pons as the cause $[3,5,9]$. Though vascular compression is the most widely accepted theory, other theories such as bioresonance have been examined [10].

Medical treatment for trigeminal neuralgia primarily consist of anticonvulsants [11]. Carbamazepine is the 
first-line treatment, and other that are used include phenytoin, oxcarbazepine and lamotrigine. Other medications that can be tried include gabapentin and baclofen. When medical treatment is ineffective, or a patient cannot tolerate the side effects, the primary surgical treatment is microvascular decompression.

Microvascular decompression is performed based on the hypothesis that compression of the trigeminal nerve is responsible for the demyelination and pain [12-15]. The procedure is performed via a retrosigmoid posterior fossa craniotomy, and the root of the trigeminal nerve is explored for signs of compression, which are then relieved by microdissection and moving the vessel causing the compression. The most common vessels identified as causing compression are the superior cerebellar artery and anterior inferior cerebellar artery [12-15]. However, there is debate regarding the cause of compression which is focused on arterial compression, venous compression, or compression secondary to adhesions [12-16].

Thus, the purpose of this study was to determine the causes of trigeminal nerve compression in patients with trigeminal neuralgia undergoing microsurgical decompression, and compare the results with examination of the trigeminal nerve in patients without symptoms of trigeminal neuralgia undergoing microdissection for hemifacial spasm.

\section{Patients and methods}

This prospective, case-controlled study included 99 patients with trigeminal neuralgia who were cured by microscopic decompression surgery at Yuquan Hospital of Tsinghua University from November 2008 to April 2010, and 101 patients with hemifacial spasm without any signs or symptoms of trigeminal neuralgia who were treated with microsurgical decompression in the same period and served as the control group. Patients with hemifacial spasm who were undergoing microdissection were chosen for the control group because the trigeminal nerve would be visible and could be examined during the course of surgery. No patient in the study had both trigeminal neuralgia and hemifacial spasm. This study was approved by the Institutional Review Board of the hospital, and all patients provided written informed consent.

All trigeminal neuralgia patients had failed or were unable to tolerate medical therapy, and some had undergone prior surgical procedures including gasserian ganglion block, nerve avulsion, retrogasserian rhizotomy, peripheral nerve block, and gamma knife surgery. Preoperative visual analogue scale (VAS) pain scores with 0 indicating no pain and 10 indicating the worst pain imaginable were obtained for trigeminal neuralgia patients. Microvascular dissection was performed in a standard manner [17]. Intraoperative findings recorded included the presence of compression and the vessel(s) causing the compression and the presence of adhesions. The relationship between the vessel and the nerve was categorized as either none, close to nerve, contact, or compression. All patients were followed up in the outpatient clinic.

Patients with hemifacial spasm also received standard microvascular dissection [18], and the trigeminal nerve was examined but not operated on. Observations of the trigeminal nerve were the same as those done for trigeminal neuralgia patients.

\section{Statistical analysis}

Categorical data were presented as number with percentage and compared using Fisher's exact test. Continuous data were presented as median with inter-quartile range (range from 25th to 75th percentiles) and compared using the Mann-Whitney test. Logistic regression model analysis was performed to find the independent impact factors of trigeminal neuralgia. Data were analyzed with using SPSS 15.0 statistics software (SPSS Inc., Chicago, IL, US), and a $p<0.05$ was considered statistically significant.

\section{Results}

A total of 99 patients (47 males and 52 females; median age: 57 years) with trigeminal neuralgia were included in the analysis. The course of trigeminal neuralgia ranged from 1 month to 30 years (median: 5 years). Eighty-five patients were treated with carbamazepine. The control group consisted of 101 patients (32 males and 69 females; median age: 47 years) with hemifacial spasm.

The characteristics of the patients in each disease group are summarized in Table 1. The patients with trigeminal neuralgia were significantly older than the patients with hemifacial spasm (median age: 57 vs. 47 years, $p<0.001$ ); $70.7 \%$ of the patients with trigeminal neuralgia were over 50 years old compared with only $41.6 \%$ of the patients with hemifacial spasm $(p<0.001)$. More males were included in the trigeminal neuralgia group than in the hemifacial spasm group (47.5 vs. $31.7 \%, p=0.03$ ).

Representative images of artery compression, vein compression, and arachnoid adhesions are shown in Fig. 1. The relative position of an artery and the trigeminal nerve was significantly associated with trigeminal neuralgia ( $p<0.001$ ) (Table 1). Among the 200 patients, 76 had an artery compressing the trigeminal nerve, and 68 of these patients had trigeminal neuralgia $(68.7 \%)$, whereas only 8 had hemifacial spasm (7.9\%). Among 37 patients noted to have arterial contact with the trigeminal nerve, 12 had trigeminal neuralgia (12.1\%) and 25 had hemifacial spasm 
Table 1 Summary for the patients characteristics by disease groups

\begin{tabular}{|c|c|c|c|}
\hline & $\begin{array}{l}\text { Trigeminal } \\
\text { neuralgia } \\
(n=99)\end{array}$ & $\begin{array}{l}\text { Hemifacial } \\
\text { spasm }(n=101)\end{array}$ & $p$ value \\
\hline Age (year) & $57.0(49.0,64.0)$ & $47.0(40.0,57.0)$ & $<0.001 *$ \\
\hline \multicolumn{4}{|l|}{ Age group } \\
\hline$\leq 30$ & $2(2.0 \%)$ & $3(3.0 \%)$ & \multirow[t]{4}{*}{$<0.001^{*}$} \\
\hline$>30-\leq 50$ & $27(27.3 \%)$ & $56(55.4 \%)$ & \\
\hline$>50-\leq 70$ & $59(59.6 \%)$ & $39(38.6 \%)$ & \\
\hline$>70$ & $11(11.1 \%)$ & $3(3.0 \%)$ & \\
\hline \multicolumn{4}{|l|}{ Gender } \\
\hline Female & $52(52.5 \%)$ & $69(68.3 \%)$ & \multirow[t]{2}{*}{$0.030 *$} \\
\hline Male & $47(47.5 \%)$ & $32(31.7 \%)$ & \\
\hline \multicolumn{4}{|l|}{ Vein } \\
\hline None & $59(59.6 \%)$ & $68(67.3 \%)$ & \multirow[t]{4}{*}{0.268} \\
\hline Close to nerve & $5(5.1 \%)$ & $9(8.9 \%)$ & \\
\hline Contact & $21(21.2 \%)$ & $13(12.9 \%)$ & \\
\hline Compression & $14(14.1 \%)$ & $11(10.9 \%)$ & \\
\hline \multicolumn{4}{|l|}{ Artery } \\
\hline None & $17(17.2 \%)$ & $58(57.4 \%)$ & \multirow[t]{4}{*}{$<0.001^{*}$} \\
\hline Close to nerve & $2(2.0 \%)$ & $10(9.9 \%)$ & \\
\hline Contact & $12(12.1 \%)$ & $25(24.8 \%)$ & \\
\hline Compression & $68(68.7 \%)$ & $8(7.9 \%)$ & \\
\hline \multicolumn{4}{|c|}{ Arachnoid adhesions } \\
\hline Yes & $3(3.0 \%)$ & $18(17.8 \%)$ & \multirow[t]{4}{*}{$<0.001 *$} \\
\hline No & $96(97.0 \%)$ & $83(82.2 \%)$ & \\
\hline $\begin{array}{l}\text { Course of the } \\
\text { disease (year) }\end{array}$ & $5.0(2.0,12.0)$ & NA & \\
\hline VAS & $7.0(7.0,9.0)$ & NA & \\
\hline
\end{tabular}

* Indicates a significant difference between disease groups

$(24.8 \%)$. Of 12 patients noted to have the artery close to but not touching the trigeminal nerve, only 2 had trigeminal neuralgia, whereas 10 had hemifacial spasm. Lastly, 21 patients were found to have arachnoid adhesions, and of these, 18 had hemifacial spasm while only 3 had trigeminal neuralgia (17.8 vs. $3.0 \%, p<0.001)$ (Table 1). There was no significant difference between the disease groups in the frequency of a vein compressing, being in contact, or being close to the nerve (Table 1).

The results of logistic regression analysis are shown in Table 2. After adjustment for age, gender, and other factors, patients with a vein compressing the nerve were more likely to have trigeminal neuralgia $(\mathrm{OR}=5.21$, $p=0.026)$ as were patients with a vein in contact with the
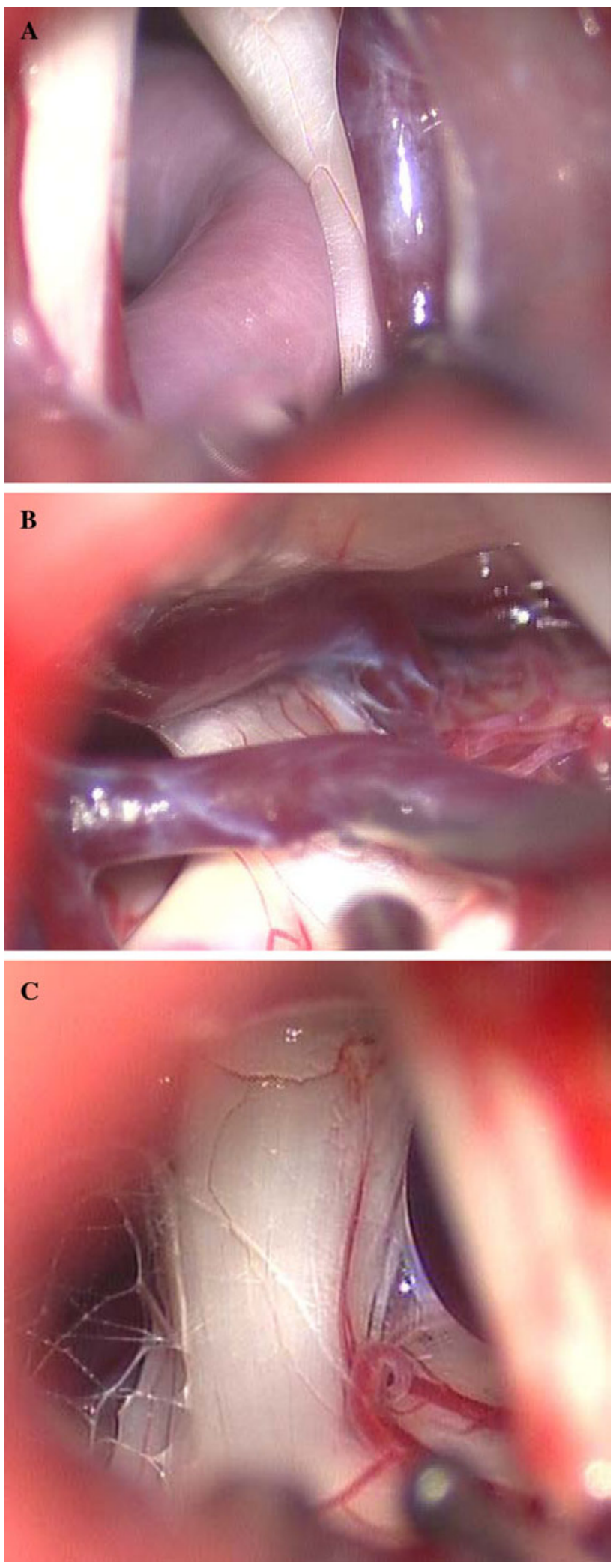

Fig. 1 Representative intraoperative images of a artery compression and vein close, $\mathbf{b}$ vein compression, and $\mathbf{c}$ arachnoid adhesions 
Table 2 Summary for the impact factors of trigeminal neuralgia

\begin{tabular}{|c|c|c|c|c|}
\hline & Crude OR (95 \% CI) & $p$ value & Adjusted OR (95 \% CI) & $p$ value \\
\hline Age (year) & $1.06(1.03,1.08)$ & $<0.001 *$ & $1.07(1.03,1.11)$ & $0.001 *$ \\
\hline \multicolumn{5}{|l|}{ Gender } \\
\hline Male & $1.95(1.10,3.47)$ & $0.023^{*}$ & $1.37(0.60,3.08)$ & 0.453 \\
\hline Female & Reference & & Reference & \\
\hline \multicolumn{5}{|l|}{ Vein } \\
\hline None & Reference & & Reference & \\
\hline Close to nerve & $0.64(0.20,2.02)$ & 0.446 & $2.69(0.61,12.00)$ & 0.193 \\
\hline Contact & $1.86(0.86,4.04)$ & 0.116 & $4.22(1.46,12.22)$ & $0.008^{*}$ \\
\hline Compression & $1.47(0.62,3.48)$ & 0.384 & $5.21(1.22,22.15)$ & $0.026^{*}$ \\
\hline \multicolumn{5}{|l|}{ Artery } \\
\hline None & Reference & & Reference & \\
\hline Close to nerve & $0.68(0.14,3.42)$ & 0.642 & $0.87(0.13,5.73)$ & 0.883 \\
\hline Contact & $1.64(0.68,3.93)$ & 0.269 & $1.69(0.56,5.12)$ & 0.351 \\
\hline Compression & $29.00(11.67,72.08)$ & $<0.001^{*}$ & $42.54(13.39,135.19)$ & $<0.001 *$ \\
\hline \multicolumn{5}{|c|}{ Arachnoid adhesions } \\
\hline Yes & $0.14(0.04,0.51)$ & $0.003 *$ & $0.15(0.03,0.90)$ & $0.038 *$ \\
\hline No & Reference & & Reference & \\
\hline
\end{tabular}

* Indicates a significant association to trigeminal neuralgia
Much of the theoretical evidence for the treatment of trigeminal neuralgia with microvascular dissection is from cadaveric anatomic studies [19]. However, anatomic changes noted in cadavers do not necessarily reflect anatomic variations seen intraoperatively. Few animal models have been developed to study compression of the trigeminal nerve root [20]. Advances in imaging techniques have allowed for detailed examination of neurovascular structures and studies in patients with trigeminal neuralgia have demonstrated contact between vessels and the trigeminal nerve [21-24]. The majority of the evidence for vascular compression of the trigeminal nerve as the cause of trigeminal neuralgia is from studies examining outcomes after microsurgical decompression [12-15, 17].

Zhang et al. [15] recently reported the results of 154 consecutive patients with trigeminal neuralgia who underwent microvascular decompression, and the initial and 5 -year pain-free rates were 84 and $72 \%$, respectively. Obvious vessel compression observed during surgery was significantly associated with long-term pain relief $(\mathrm{OR}=3.2)$. Sekula et al. [12] reported that 31 of 36 patients $(86 \%)$ with a mean age of 73 years had excellent outcomes after microvascular decompression for trigeminal neuralgia. Tucer et al. [13] reported good outcomes in 37 patients who received microvascular decompression for trigeminal neuralgia, and found that the only factors affecting prognosis of the surgery were intraoperative detection of compression and signs of compression on preoperative magnetic resonance imaging (MRI) and MR 
angiography (MRA) studies. Oesman and Mooij [14] also reported good results of microvascular decompression, and that immediate resolution of symptoms postoperatively was the most important predictor of long-term relief of pain. Despite the encouraging results of individual studies, a recent Cochrane systematic review by Zakrzewska and Coakham [25] found that although microvascular decompression is likely the most effective therapy in correctly diagnosed patients, high-quality prospective studies are lacking.

Vein compression is frequently found during surgery in patients with trigeminal neuralgia, but in many cases the site of vein compression is not consistent with the area of pain, and decompression of the vein by moving the vessel of ligation with electrocoagulation does not resolve the symptoms or only transient improvement is observed. Few studies, have reported trigeminal neuralgia due to venous compression alone [16]. During microvascular dissection, manipulation of the veins is associated with a risk of rupture and ligation of the veins may result in the obstruction of venous return in the brainstem and cerebellum, or possible congestive cerebral infarction. Our finding that trigeminal neuralgia was not associated with venous compression indicates that there might be no requirement for special treatment of the veins, which may reduce the risk for venous injury and venous return obstruction. Since most arteries are tortuous, and their stiffness increases with age, this increasing stiffness can result in compression of the root of the trigeminal nerve, leading to demyelination and subsequent trigeminal neuralgia. On the contrary, veins do not bear high blood pressure, their walls are thin, and their location is relatively fixed, and thus, veins tend not to become stiff and/or tortuous with age and are therefore not likely to cause compression of the nerve.

\section{Conclusions}

The findings of this study indicate that compression of the trigeminal nerve from veins was not a cause of trigeminal neuralgia. These results indicate that while in patients with arterial compression of nerve, complete decompression is required and removal of adhesions is also necessary, treatment of the vein may not need to be a priority when performing microvascular dissection.

\section{Conflict of interest None.}

Open Access This article is distributed under the terms of the Creative Commons Attribution License which permits any use, distribution, and reproduction in any medium, provided the original author(s) and the source are credited.

\section{References}

1. Tronnier VM, Rasche D, Hamer J, Kienle AL, Kunze S et al (2001) Treatment of idiopathic trigeminal neuralgia: comparisonof long-term outcome after radiofrequency rhizotomy and microvascular decompression. Neurosurgery 48:1261-1268

2. Kabatas S, Albayrak SB, Cansever T, Hepgul KT et al (2009) Microvascular decompression as a surgical managementfor trigeminal neuralgia: a critical review of the literature. Neurol India 57:134-138

3. Love S, Coakham HB (2001) Trigeminal neuralgia: pathology and pathogenesis. Brain 124:2347-2360

4. Bennetto L, Patel NK, Fuller G (2007) Trigeminal neuralgia and its management. BMJ 334:201-205

5. Nurmikko TJ, Eldridge PR et al (2001) Trigeminal neuralgiapathophysiology, diagnosis and current treatment. Br J Anaesth 87:117-132

6. Dhople AA, Adams JR, Maggio WW, Naqvi SA, Regine WF, Kwok Y et al (2009) Long-term outcomes of Gamma Knife radiosurgery for classic trigeminal neuralgia: implications of treatment and critical review of the literature. J Neurosurg 111:351-358

7. Krafft RM (2008) Trigeminal neuralgia. Am Fam Physician 2008(77):1291-1296

8. Dandy WE (1934) Concerning the cause of trigeminal neuralgia. Am J Surg 1934(24):447-455

9. Lunsford LD, Apfelbaum RI et al (1985) Choice of surgical therapeutic modalities for treatment of trigeminalneuralgia. Clin Neurosurg 32:319-333

10. Jia DZ, Li G et al (2010) Bioresonance hypothesis: a new mechanism on the pathogenesis of trigeminal neuralgia. Med Hypotheses 74:505-507

11. Larsen A, Piepgras D, Chyatte D, Rizzolo D et al (2011) Trigeminal neuralgia: diagnosis and medical and surgical management. JAAPA 24:20-25

12. Sekula RF Jr, Frederickson AM, Jannetta PJ, Quigley MR, Aziz KM, Arnone GD et al (2011) Microvascular decompression for elderly patients with trigeminal neuralgia: a prospective study and systematic review with meta-analysis. J Neurosurg 114:172-179

13. Tucer B, Ekici MA, Demirel S, Başarslan SK, Koç RK, Güçlü B et al (2012) Microvascular decompression for primary trigeminal neuralgia: short-term follow-up results and prognostic factors. J Korean Neurosurg Soc 52:42-47

14. Oesman C, Mooij JJ et al (2011) Long-term follow-up of microvascular decompression for trigeminal neuralgia. Skull Base 21:313-322

15. Zhang H, Lei D, You C, Mao BY, Wu B, Fang Y (2012) The long-term outcome predictors of pure microvascular decompression for primary trigeminal neuralgia. World Neurosurg 2012 Jan 26. [Epub ahead of print]

16. Hong W, Zheng X, Wu Z, Li X, Wang X, Li Y, Zhang W, Zhong J, Hua X, Li S et al (2011) Clinical features and surgical treatment of trigeminal neuralgia caused solely by venous compression. Acta Neurochir (Wien) 153:1037-1042

17. Tomasello F, Alafaci C, Angileri FF, Calisto A, Salpietro FM et al (2008) Clinical presentation of trigeminal neuralgia and the rationale of microvascular decompression. Neurol Sci 29(Suppl 1):S191-S195

18. Hyun SJ, Kong DS, Park K (2010) Microvascular decompression for treating hemifacial spasm: lessons learned from a prospective study of 1,174 operations. Neurosurg Rev 33:325-334 discussion 334

19. Guclu B, Sindou M, Meyronet D, Streichenberger N, Simon E, Mertens P et al (2011) Cranial nerve vascular compression 
syndromes of the trigeminal, facial and vago-glossopharyngeal nerves: comparative anatomical study of the central myelin portion and transitional zone; correlations with incidences of corresponding hyperactive dysfunctional syndromes. Acta Neurochir (Wien) 153:2365-2375

20. Luo DS, Zhang T, Zuo CX, Zuo ZF, Li H, Wu SX, Wang W, Li YQ et al (2012) An animal model for trigeminal neuralgia by compression of the trigeminal nerve root. Pain Physician 15:187-196

21. Zhou Q, Liu ZL, Qu CC, Ni SL, Xue F, Zeng QS et al (2012) Preoperative demonstration of neurovascular relationship in trigeminal neuralgia by using 3D FIESTA sequence. Magn Reson Imaging 30:666-671

22. Leal PR, Roch JA, Hermier M, Souza MA, Cristino-Filho G, Sindou M et al (2011) Structural abnormalities of the trigeminal root revealed by diffusion tensor imaging in patients with trigeminal neuralgia caused by neurovascular compression: a prospective, double-blind, controlled study. Pain 152:23572364

23. Leal PR, Hermier M, Froment JC, Souza MA, Cristino-Filho G, Sindou M et al (2010) Preoperative demonstration of the neurovascular compression characteristics with special emphasis on the degree of compression, using high-resolution magnetic resonance imaging: a prospective study, with comparison to surgical findings, in 100 consecutive patients who underwent microvascular decompression for trigeminal neuralgia. Acta Neurochir (Wien) 152:817-825

24. Kakizawa Y, Seguchi T, Kodama K, Ogiwara T, Sasaki T, Goto $\mathrm{T}$, Hongo $\mathrm{K}$ et al (2008) Anatomical study of the trigeminal and facial cranial nerves with the aid of 3.0-tesla magnetic resonance imaging. J Neurosurg 108:483-490

25. Zakrzewska JM, Coakham HB (2012) Microvascular decompression for trigeminal neuralgia: update. Curr Opin Neurol 25:296-301 